\title{
Commentary ICU admission and severity assessment in community-acquired pneumonia
} James D Chalmers

Queens Medical Research Institute, Centre for Inflammation Research, Little France, Edinburgh EH16 4TJ, UK

Corresponding author: James D Chalmers, jamesdchalmers@googlemail.com

Published: 15 June 2009

Critical Care 2009, 13:156 (doi:10.1186/cc7889)

This article is online at http://ccforum.com/content/13/3/156

(c) 2009 BioMed Central Ltd

See related research by Renaud et al., http://ccforum.com/content/13/2/R54

\begin{abstract}
The past 15 years have seen major advances in our understanding of severity assessment in community-acquired pneumonia (CAP). Prognostic tools have been promoted to guide all major management decisions in CAP, including admission to the critical care unit. Several recent studies, including the study by Renaud and colleagues, have challenged us to re-evaluate how we consider severe CAP, a concept for which there is still no universally accepted definition. Existing severity scores such as the Pneumonia Severity Index and the CURB65 score are designed to predict 30-day mortality. As a result, they are heavily weighted by age and co-morbidity. They perform less well when predicting other outcomes such as requirement for ICU admission and are of limited use in the critical care environment. This commentary discusses recent attempts to develop useful severity criteria to guide the use of ICU resources in patients with severe CAP.
\end{abstract}

The past 15 years have seen major advances in our understanding of severity assessment in community-acquired pneumonia (CAP). Prognostic tools have been promoted to guide all major management decisions in CAP, including admission to the critical care unit.

Several recent studies, including the study by Renaud and colleagues [1], have challenged us to re-evaluate how we consider severe CAP, a concept for which there is still no universally accepted definition.

Since the development of the Pneumonia Severity Index in 1997 [2], severe CAP has been considered in terms of a patient's risk of 30-day mortality - determined by a combination of age, co-morbidities and physiological parameters measured on admission. The two most widely used scores, the Pneumonia Severity Index and the CURB65 score [3], were developed to predict 30-day mortality.
It is recognised that the majority of pneumonia mortality occurs in older people, however, and that many patients who die are treated palliatively [4]. Nearly $50 \%$ of all deaths in patients with pneumonia and more than one-quarter of deaths within 30 days are related to co-morbidities rather than being directly pneumonia related [5].

These scores therefore have important limitations arising from the use of 30-day mortality as an outcome. The scores may underestimate severity in young people [6] and they perform less well when considering outcomes such as intensive care unit (ICU) admission or requirement for mechanical ventilation or vasopressor support [7-9]. As few as 20\% of patients in the highest Pneumonia Severity Index class (class V) require ICU admission, illustrating the system's limited value for the critical care community [9].

There is a growing consensus that ICU admission and, more specifically, mechanical ventilation or vasopressor support are more useful outcomes than 30-day mortality to define severe CAP and to identify the most acute ill patients [7,10-12]. The requirement for mechanical ventilation or vasopressor support is preferred to simply using ICU admission, as evidence suggests that ICU admission rates and criteria vary widely across different healthcare systems. This helps to explain why we see ICU admission rates of $17 \%$ in Spain [13] compared with $8.7 \%$ in the UK or $4 \%$ in Hong Kong [14].

What scoring system should we used to identify patients requiring ICU admission? The revised British Thoracic Society CAP guidelines are due to be published in 2009 and will recommend using the CURB65 criteria to determine ICU admission. The Infectious Disease Society of AmericaAmerican Thoracic Society guidelines recommend the revised

$\mathrm{CAP}=$ community-acquired pneumonia; CURB $65=$ Confusion, Urea $>7 \mathrm{mmol} / \mathrm{l}$, Respiratory rate $\geq 30 / \mathrm{min}$, Blood pressure $<90 \mathrm{mmHg}$ systolic and/or diastolic blood pressure $\leq 60 \mathrm{mmHg}$, and age $\geq 65$ years; ICU = intensive care unit; SMART-COP = Systolic blood pressure, Multilobar chest radiograph involvement, Albumin, Respiratory rate, Tachycardia, Confusion, Oxygenation and arterial pH. 
American Thoracic Society criteria, which comprise two major criteria (the requirement for mechanical ventilation and vasopressor support) or three minor criteria (comprising respiratory rate, $\mathrm{PaO}_{2} / \mathrm{FiO}_{2}$ ratio, multilobar infiltrates, confusion, uraemia, leucopenia, thrombocytopenia, hypothermia and hypotension requiring aggressive fluid resuscitation) [15].

Alongside these criteria, Renaud and colleagues [1], Charles and colleagues [11] and Espana and colleagues [12] have all independently described scoring systems designed to predict ICU admission in large databases. It is reassuring that the high-risk features identified in each of these studies are similar, with acidosis, systolic blood pressure, respiratory rate, uraemia, confusion, hypoxaemia and multilobar infiltrates featuring in each of the derived scores. The abundance of severity criteria, however, reveals the lack of consensus over which patients should be initially managed in the ICU.

The majority of admissions to the ICU occur within the first 24 hours. Delayed transfer to the ICU is associated with increased mortality, and therefore early recognition of these patients is important. The Risk of Early Admission to Intensive Care Unit Score has been shown to predict patients with delayed admission to the ICU. This group probably consists of patients in whom severity was underestimated on admission, of patients with treatment failure and of patients with unstable co-morbidities and nosocomial superinfection. Further studies in this group are required.

All of the new scores are complex, making them difficult to implement in clinical practice. Evidence suggests that current severity criteria, such as the CURB65 score, are underutilised. It may therefore be impractical to expect staff to use the CURB65 score to decide on the site of care, then use SMART-COP or the American Thoracic Society criteria to decide whether a patient requires ICU care, and then use the Risk of Early Admission to Intensive Care Unit Score to assess their risk of requiring ICU subsequently. A more practical approach to severity assessment is needed.

A perfect scoring system may not exist, but it should ideally predict both 30-day mortality and the requirement for mechanical ventilation or vasopressor support. The scoring system should be simple, composed of the fewest possible factors, and easy to remember in a busy emergency department. The system should function equally well in older patients and young patients, and should be based on physiological derangement and organ dysfunction rather than on age or co-morbidities. In addition, scoring systems need to classify patients into distinct management groups.

The hope is that future studies can identify physiological scoring systems or biomarkers that can achieve these goals and provide an effective adjunct to clinical judgement in the early management of CAP.

\section{Competing interests}

The author declares that they have no competing interests.

\section{References}

1. Renaud B, Labarère J, Coma E, Santin A, Hayon J, Gurgui M, Camus N, Roupie E, Hémery F, Hervé J, Salloum M, Fine MJ, Brun-Buisson C: Risk stratification of early admission to the intensive care unit of patients with no major criteria of severe community acquired pneumonia: development of an international prediction rule. Crit Care 2009, 13:R54.

2. Fine MJ, Auble TE, Yealy DM, Hanusa BH, Weissfeld LA, Singer DE, Coley CM, Marrie TJ, Kapoor WN: A prediction rule to identify low-risk patients with community-acquired pneumonia. $N$ Engl J Med 1997, 336:243-250.

3. Lim WS, van der Eerden MM, Laing R, Boersma WG, Karalus N Town GI, Lewis SA, MacFarlane JT: Defining community acquired pneumonia severity on presentation to hospital: an international derivation and validation study. Thorax 2003, 58: 377-382.

4. Marrie TJ, Fine MJ, Kapoor WN, Coley CM, Singer DE, Obrosky DS: Community-acquired pneumonia and do not resuscitate orders. J Am Geriatr Soc 2002, 50:290-299.

5. Mortensen EM, Coley CM, Singer DE, Marrie TJ, Obrosky DS, Kapoor WN, Fine MJ: Causes of death for patients with community-acquired pneumonia: results from the Pneumonia Patients Outcomes Research Team cohort study. Arch Intern Med 2002, 13:1059-1064.

6. Chalmers JD, Singanayagam A, Hill AT: Predicting the need for mechanical ventilation and/or inotropic support in young adults admitted with community acquired pneumonia. Clin Infect Dis 2008, 47:1571-1574.

7. Buising KL, Thursky KA, Black JF, MacGregor L, Street AC, Kennedy MP, Brown GV: A prospective comparison of severity scores for identifying patients with severe community acquired pneumonia: reconsidering what is meant by severe pneumonia. Thorax 2006, 61:419-424.

8. Angus DC, Marrie TJ, Obrosky DS, Clermont G, Dremsizov TT, Coley C, Fine MJ, Singer DE, Kapoor WN: Severe community acquired pneumonia. Use of intensive care services and evaluation of American and British Thoracic Society diagnostic criteria. Am J Respir Crit Care Med 2002, 166:717-723.

9. Valencia M, Badia JR, Cavalcanti M, Ferrer M, Agusti C, Angrill J, Garcia E, Mensa J, Niederman MS, Torres A: Pneumonia Severity Index class V patients with community-acquired pneumonia. Characteristics, outcomes and value of severity scores. Chest 2007, 132:515-522.

10. Chalmers JD, Singanayagam A, Hill AT: Systolic blood pressure is superior to other haemodynamic predictors of outcome in community acquired pneumonia. Thorax 2008, 63:698-702.

11. Charles PG, Wolfe R, Whitby M, Fine MJ, Fuller AJ, Stirling R, Wright AA, Ramirez JA, Christiansen KJ, Waterer GW, Pierce RJ, Armstrong JG, Korman TM, Holmes P, Obrosky DS, Peyrani P, Johnson B, Hooy M, Grayson MI: SMART-COP: a tool for predicting the need for intensive respiratory or vasopressor support in community-acquired pneumonia. Clin Infect Dis 2008, 47:375-384.

12. Espana PP, Capelastegui A, Gorordo I, Esteban C, Oribe M, Ortega M, Bilbao A, Quintana JM: Development and validation of a clinical prediction rule for severe community-acquired pneumonia. Am J Respir Crit Care Med 2006, 174:1249-1256.

13. Ewig S, de Roux A, Bauer T, Garcia E, Mensa J, Niederman M, Torres A: Validation of predictive rules and indices of severity for community acquired pneumonia. Thorax 2004, 59:421-427.

14. Man SY, Lee N, Ip M, Ip M, Antonio GE, Chau SS, Mak P, Graham CA, Zhang M, Lui G, Chan PK, Ahuja AT, Hui DS, Sung JJ, Rainer $\mathrm{TH}$ : Prospective comparison of three predictive rules for assessing severity of community-acquired pneumonia in Hong Kong. Thorax 2007, 62:348-353.

15. Mandell LA, Wunderink RG, Anzueto A, Bartlett JG, Campbell GD, Dean NC, Dowell SF, File TM Jr, Musher DM, Niederman MS, Torres A, Whitney CG: Infectious Disease Society of American/American Thoracic Society consensus guidelines for the management of community acquired pneumonia in adults. Clin Infect Dis 2007, 44:S27-S72. 